\title{
The Frail Dialysis Population: A Growing Burden for the Dialysis Community
}

\author{
Kirsten L. Johansen ${ }^{\mathrm{a}, \mathrm{b}}$ \\ ${ }^{a}$ Division of Nephrology, University of California, San Francisco, CA, USA; ${ }^{b}$ Nephrology Section, San Francisco \\ Veterans Affairs Medical Center, San Francisco, CA, USA
}

\section{Key Words}

Frailty · Dialysis · End-stage renal disease

\begin{abstract}
Background: The dialysis population is aging worldwide. It is well known that patients on dialysis have limited functional status, but only recently has frailty been considered. Summary: The prevalence of frailty among patients on dialysis ranges from 3.4- to 10-fold higher than among community-dwelling elderly, depending on the method of assessing frailty and patient characteristics. Despite its high prevalence and the high overall mortality in the dialysis population, frailty is associated with higher mortality, independent of clinical and demographic characteristics and comorbidity. The prevalence of frailty among patients with nondialysis-dependent chronic kidney disease (CKD) is also high, and cross-sectional data suggest that the prevalence may increase as CKD progresses. Thus, interventions to improve frailty have the potential to improve quality of life and mortality. Although interventions to improve physical dysfunction have been successful in the population with end-stage renal disease, no studies have specifically targeted frail individuals. Therefore, the extent to which exercise or physical activity interventions are feasible among frail patients and can improve frailty urgently needs to be examined. In the
\end{abstract}

meantime, providers should refer frail patients to physical therapists and encourage them to be more active if possible. In addition, more attention should be focused on the possibility that rehabilitation among patients with earlier stages of CKD could improve dialysis outcomes. Key Messages: Frailty is extremely common among patients on dialysis and is independently associated with adverse outcomes. Providers should take advantage of available resources to improve functioning in this population, and research should address the optimal strategy for addressing frailty, including timing of intervention.

C 2015 S. Karger AG, Basel

\section{Aging Dialysis Population}

The mean age of the dialysis population has been increasing in Japan and the United States over the last decade (fig. 1) [1,2]. Japan's incident and prevalent dialysis populations (67.8 and 66.6 years at the end of 2011) are considerably older than the US dialysis population and likely the dialysis populations of most other countries in the world. Sixty-three percent of Japanese dialysis patients are 65 years or older, and $36 \%$ are 75 or above [2]. Therefore, it is becoming important for dialysis practitioners to understand syndromes common among the elderly.

\section{KARGER 125}

(c) 2015 S. Karger AG, Base

0253-5068/15/0404-0288\$39.50/0

E-Mail karger@karger.com

www.karger.com/bpu
Kirsten L. Johansen, MD

Nephrology Section, 111J San Francisco VA Medical Center 4150 Clement Street

San Francisco, CA 94127 (USA)

E-Mail kirsten.johansen@ucsf.edu 


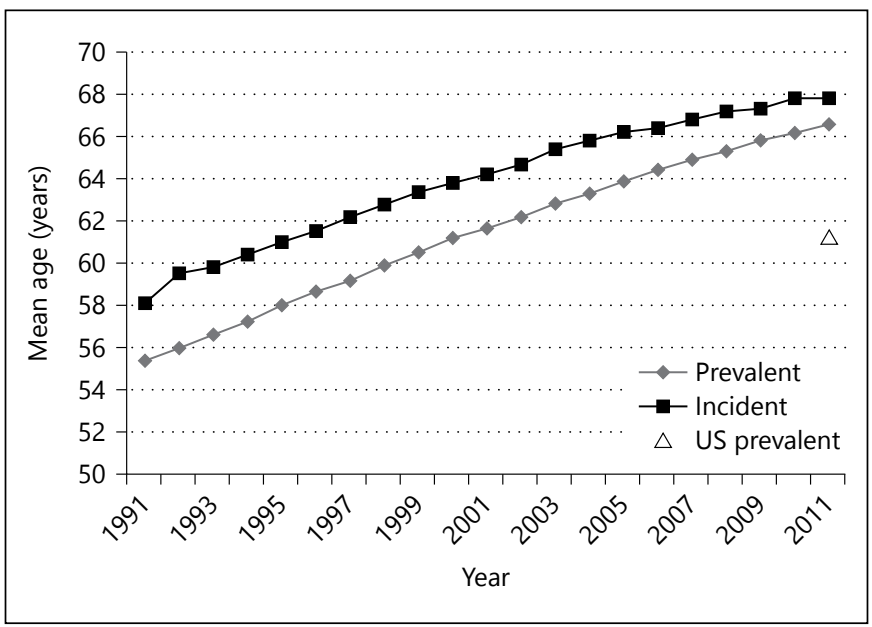

Fig. 1. Mean age of incident and prevalent dialysis patients in Japan by year. Black line represents incident patients; gray line indicates prevalent patients; open triangle shows the US prevalent population in 2011 for comparison.

\section{What Is Frailty?}

A recent consensus conference of European and American frailty experts defined frailty as a medical syndrome with multiple causes and contributors that is characterized by diminished strength, endurance, and reduced physiologic function that increases an individual's vulnerability for developing increased dependency and/ or death [3]. Aging and chronic diseases likely contribute to the development of frailty through mechanisms that include oxidative stress, inflammation, and reductions in anabolic hormones [4]. Thus, it is not surprising that chronic kidney disease (CKD), which itself can lead to all of these perturbations, is associated with a higher prevalence of frailty among community-dwelling elderly [5].

Operational definitions of frailty have incorporated the concepts of multiple contributing causes and multiple manifestations forming a syndrome. Fried et al. [6] developed a frailty phenotype consisting of three or more of: unintentional weight loss, exhaustion, physical inactivity, slow gait speed, and weak grip strength. According to this definition, approximately $7 \%$ of community-dwelling elders in a large US cohort study were frail, and frailty was associated with female sex, older age, and higher burden of comorbidity. In order to apply the concept of frailty to pre-existing cohorts of elders or patients with CKD or end-stage renal disease (ESRD), the frailty phenotype has been adapted in numerous ways, the most common of which is to substitute patients' self-report of physical functioning for direct measures of physical performance $[7,8]$.

\section{Prevalence of Frailty in the Dialysis Population}

Using such a self-report-based definition of frailty, we assessed the prevalence and significance of frailty among incident dialysis patients participating in the United States Renal Data Systems Dialysis Morbidity and Mortality Study [8]. Two-thirds of the patients were frail, including many who were under the age of 65 years. Older patients, women, and patients with diabetes mellitus were more likely to be frail. Frailty was associated with $>3$-fold higher risk of death in univariate analysis (hazard ratio [HR] 3.42, 95\% confidence interval [CI] 2.45-4.76, p < 0.001 ) that persisted in multivariable analysis (HR 2.24, $95 \%$ CI $1.60-3.15, \mathrm{p}<0.001)$. Since then, the Fried frailty phenotype has been applied in prevalent dialysis populations in the US $[9,10]$. The prevalence was lower by this method at $30-42 \%$, but was still 4-6 times that of healthy elderly despite inclusion of all adults in these studies rather than only those older than age 65 . The prevalence of frailty in patients with ESRD has varied across cohorts, likely as a result of differences in the method of assessing frailty (table 1). Differences in patient characteristics, such as dialysis vintage or degree of comorbidity probably also contribute to the variation. Nevertheless, all studies have shown a prevalence of frailty that is substantially higher than among community-dwelling elderly.

Given the high burden of comorbid illness among patients on dialysis and the high overall mortality, it is important to consider whether frailty provides prognostic information in this population. If comorbidity and markers of inflammation already in use in the dialysis population capture the risk associated with frailty, then frailty may not improve prediction of adverse outcomes. However, frailty was independently associated with higher mortality in all studies that have examined the association to date. Furthermore, frailty has also been found to be associated with higher risk of falls and fractures [11, 12]. There is ongoing debate about the value of frailty assessment in the dialysis population and the method by which frailty should be assessed [13, 14], and longitudinal studies are needed to address these questions.

\section{Time Course of Development of Frailty among Patients with CKD}

Although there have been no longitudinal reports of frailty among patients with CKD, cross-sectional studies suggest that frailty increases as eGFR declines (table 2). Dalrymple et al. [15] examined the association of stages 
Table 1. Studies of frailty among patients with ESRD

\begin{tabular}{|c|c|c|c|c|c|c|c|}
\hline Reference & Population & Weight loss & Exhaustion & Physical activity & Gait speed & Grip strength & Prevalence, \% \\
\hline $\begin{array}{l}\text { Johansen, } \\
2007 \text { [34] }\end{array}$ & Incident dialysis & $\begin{array}{l}\text { Malnourished } \\
\text { according to } \\
\text { provider } \\
\text { assessment }\end{array}$ & SF-36 Vitality & $\begin{array}{l}\text { Inactive (single } \\
\text { question about } \\
\text { frequency of } \\
\text { activity) }\end{array}$ & SF-36 PF scale & SF-36 PF scale & 67.7 \\
\hline $\begin{array}{l}\text { Bao et al., } \\
2012 \text { [35] }\end{array}$ & Incident HD & No & SF-12 Vitality & $\begin{array}{l}\text { Human Activity } \\
\text { Profile }\end{array}$ & SF-12 PF & SF-12 PF & 73 \\
\hline $\begin{array}{l}\text { Johansen et al., } \\
2014 \text { [37] }\end{array}$ & Prevalent HD & Yes & CES-D & MMLTA & $>15$ feet & Yes & 30 \\
\hline $\begin{array}{l}\text { Johansen et al., } \\
2014 \text { [14] }\end{array}$ & Prevalent HD & Yes & SF-36 Vitality & MMLTA & SF-36 PF & SF-36 PF & 53 \\
\hline
\end{tabular}

SF-36 = Medical Outcomes Study Short Form 36-item Survey; HD = hemodialysis; SF-12 = Medical Outcomes Short Form 12-item Survey; PF = Physical Functioning; CES-D = Center for Epidemiologic Studies Depression Scale; MMLTA = Modified Minnesota Leisure Time Activity Questionnaire; BMI = body mass index.

Table 2. Studies of frailty among patients with non-dialysis requiring CKD

\begin{tabular}{|c|c|c|c|c|c|c|c|}
\hline Reference & Population & Weight loss & Exhaustion & Physical activity & Gait speed & Grip strength & Prevalence, \% \\
\hline $\begin{array}{l}\text { Shlipak et al., } \\
2004[38]\end{array}$ & $\begin{array}{l}\text { Community-dwelling } \\
\text { elderly CHS participants } \\
\text { with } \mathrm{SCr} \geq 1.3 \text { in women } \\
\text { and } \geq 1.5 \text { in men }\end{array}$ & Yes & CES-D & MMLTA & $>15$ feet & Yes & 15 \\
\hline $\begin{array}{l}\text { Wilhelm-Leen } \\
\text { et al., } 2009 \text { [39] }\end{array}$ & $\begin{array}{l}\text { Adults with eGFR } \\
<45 \mathrm{ml} / \mathrm{min} / 1.73 \mathrm{~m}^{2} \text { from } \\
\text { NHANES III }\end{array}$ & $\begin{array}{l}\mathrm{BMI} \leq 18.5 \\
\mathrm{~kg} / \mathrm{m}^{2}\end{array}$ & $\begin{array}{l}\text { Self-report of } \\
\text { difficulty walking } \\
\text { short distances }\end{array}$ & $\begin{array}{l}\text { Self-report of 'less } \\
\text { active' than peers }\end{array}$ & $>8$ feet & Self-report & 20.9 \\
\hline $\begin{array}{l}\text { Roshanravan } \\
\text { et al., } 2012[16]\end{array}$ & $\begin{array}{l}\text { Stages } 1-4 \text { CKD (mean } \\
\left.\text { eGFR } 51 \mathrm{ml} / \mathrm{min} / 1.73 \mathrm{~m}^{2}\right)\end{array}$ & Yes & SF-36 Vitality & $\begin{array}{l}\text { Self-reported exercise } \\
<1 \text { time/week }\end{array}$ & Yes & Yes & 14 \\
\hline $\begin{array}{l}\text { Dalrymple } \\
\text { et al., } 2013 \text { [15] }\end{array}$ & $\begin{array}{l}\text { CHS participants with } \\
\text { eGFR }<45 \mathrm{ml} / \mathrm{min} / 1.73 \mathrm{~m}^{2} \\
\text { by cystatin } \mathrm{C}\end{array}$ & Yes & CES-D & MMLTA & $>15$ feet & Yes & 24 \\
\hline
\end{tabular}

NHANES = National Health and Nutrition Examination Survey; CHS = Cardiovascular Health Study; CRIC = Chronic Renal Insufficiency Cohort; MESA = Multi-Ethnic Study of Atherosclerosis.

of CKD defined using Cystatin C and frailty by the Fried phenotype and found a strong linear correlation, with a higher prevalence of frailty at more advanced stages of CKD. Similarly, Roshanravan et al. [16] found that the estimated glomerular filtration rate (eGFR) categories of
$<30 \mathrm{ml} / \mathrm{min} / 1.73 \mathrm{~m}^{2}$ and $30-44 \mathrm{ml} / \mathrm{min} / 1.73 \mathrm{~m}^{2}$ were associated with a 2.8 -fold (95\% CI 1.3-6.3) and 2.1-fold (95\% CI 1.0-4.7) higher prevalence of frailty compared with $\mathrm{eGFR} \geq 60 \mathrm{ml} / \mathrm{min} / 1.73 \mathrm{~m}^{2}$. In this study, frailty was associated with higher odds of death or initiation of di- 
alysis therapy. A recent report from the Chronic Renal Insufficiency Cohort also found that the prevalence of frailty was higher among patients with lower eGFR [17]. The suggestion from these data that frailty may progress along with CKD progression and is also associated with onset of CKD fits with data from other studies showing the highest prevalence of frailty among patients on dialysis. Thus, the dialysis population is aging with a high proportion of frail individuals.

\section{Can Frailty Be Addressed?}

We are aware of no published studies specifically designed to address frailty in the dialysis population. Unfortunately, recent studies suggest that functional status declines further after initiation of dialysis among frail and very elderly patients without intervention $[18,19]$, making it imperative that we consider treatments or interventions to reverse the downward trajectory. Since physical inactivity is a part of the definition of frailty, it is possible that interventions to increase activity could address frailty directly or indirectly if they also improve physical performance or symptoms of fatigue and exhaustion. Numerous studies have shown that patients on hemodialysis are extremely inactive [20-22] and that low physical activity is associated with worse physical performance [23] and with lower survival $[22,24,25]$. Few studies have focused on increasing habitual physical activity in the dialysis population $[26,27]$, but such a strategy seems promising and should be investigated. Even without solid evidence for a benefit in the dialysis population, patients should be encouraged to follow physical activity guidelines for older patients if possible.

There have been numerous studies of more vigorous exercise training programs designed to increase exercise capacity or physical performance [28], and although many studies are small and/or of low quality, the majority have led to improvements. Furthermore, patients with lower baseline functioning derived greater benefit in one of the largest exercise intervention studies [29]. Therefore, aerobic exercise training would seem to have the potential to improve frailty. However, the vigorous nature of such training programs has led to the exclusion of large numbers of patients on hemodialysis as ineligible, and frail patients would more likely have factors that lead to exclusion. In addition, there has been a high rate of patient refusal to participate in such programs when offered [30], suggesting that fear or reluctance to do vigorous activity is a barrier for patients' adoption of exercise programs. Thus, the extent to which aerobic exercise training during dialysis or at another time will be able to reverse frailty remains to be seen.

Because weakness is part of frailty and muscle atrophy is a key underlying mechanism $[10,31]$, resistance exercise or other anabolic interventions might be logical choices to ameliorate frailty in the dialysis population [32]. Indeed, resistance training has been shown to increase muscle strength among patients on hemodialysis [32] as well as among institutionalized nonagenarians [33], proving that such programs are possible even among patients with extremely low functioning and can be beneficial. Therefore, referral of frail individuals for physical therapy and strength training should be strongly considered when weakness or frailty is detected.

\section{Conclusion}

Frailty is common in the aging dialysis population and is associated with adverse outcomes including death, hospitalization, falls, and fractures. Frailty is also more common among individuals with CKD than those without and appears to progress as CKD progresses. Studies are needed to determine whether interventions can improve frailty, which interventions are most successful, and when such interventions should be applied. The frequent onset of frailty in CKD before dialysis and the potential association of frailty with higher risk of ESRD would suggest that intervention in predialysis stages of CKD may be of most benefit, but it is also important to consider the dialysis population whose functioning is currently extremely impaired.

\section{Conflicts of Interest}

The author declares no conflicts of interest in relation to this work.
References
1 United States Renal Data System: Chapter 1: Incidence, prevalence, patient characteristics, and treatment modalities. Am J Kidney Dis 2015;66(suppl 1):S93-S110.
-2 Nakai S, Hanafusa N, Masakane I, Taniguchi M, Hamano T, Shoji T, Hasegawa T, Itami N, Yamagata K, Shinoda T, Kazama JJ, Wata- nabe Y, Shigematsu T, Marubayashi S, Mori- ta O, Wada A, Hashimoto S, Suzuki K, Naka- moto H, Kimata N, Wakai K, Fujii N, Ogata S, Tsuchida K, Nishi H, Iseki K, Tsubakihara Y: An overview of regular dialysis treatment in Japan (as of 31 December 2012). Ther Apher Dial 2014;18:535-602. 
-3 Morley JE, Vellas B, van Kan GA, Anker SD, Bauer JM, Bernabei R, Cesari M, Chumlea WC, Doehner W, Evans J, Fried LP, Guralnik JM, Katz PR, Malmstrom TK, McCarter RJ, Gutierrez Robledo LM, Rockwood K, von Haehling S, Vandewoude MF, Walston J: Frailty consensus: a call to action. J Am Med Dir Assoc 2013;14:392-397.

4 Fried L, Ferrucci L, Darer J, Williamson J, Anderson G: Untangling the concepts of disability, frailty, and comorbidity: implications for improved targeting and care. J Gerontol A Biol Med Sci 2004;59:255-263.

5 Shlipak M, Stehman-Breen C, Fried L, Song X, Siscovick D, Fried L, Psaty B, Newman A: The presence of frailty in elderly persons with chronic renal insufficiency. Am J Kidney Dis 2004;43:861-867.

-6 Fried L, Tangen C, Walston J, Newman A, Hirsch C, Gottdiener J, Seeman T, Tracy R, Kop W, Burke G, McBurnie M: Frailty in older adults: evidence for a phenotype. J Gerontol A Biol Med Sci 2001;56A:M146-M156.

7 Woods N, LaCroix A, Gray S, Aragaki A, Cochrane B, Brunner R, Masaki K, Murray A, Newman AB: Frailty: emergence and consequences in women aged 65 and older in the Women's Health Initiative Observational Study. J Am Geriatr Soc 2005;53: 1321-1330.

$\checkmark 8$ Johansen KL, Chertow GM, Jin C, Kutner NG: Significance of frailty among dialysis patients. J Am Soc Nephrol 2007;18:2960-2967.

-9 McAdams-Demarco MA, Law A, Salter ML, Boyarsky B, Gimenez L, Jaar BG, Walston JD, Segev DL: Frailty as a novel predictor of mortality and hospitalization in individuals of all ages undergoing hemodialysis. J Am Geriatr Soc 2013;61:896-901.

10 Johansen KL, Dalrymple LS, Delgado C, Kaysen GA, Kornak J, Grimes B, Chertow GM: Association between body composition and frailty among prevalent hemodialysis patients: A USRDS special study. J Am Soc Nephrol 2014;25:381-389.

-11 McAdams-DeMarco MA, Suresh S, Law A, Salter ML, Gimenez LF, Jaar BG, Walston JD, Segev DL: Frailty and falls among adult patients undergoing chronic hemodialysis: a prospective cohort study. BMC Nephrol 2013;14:224.

12 Delgado C, Shieh S, Grimes B, Chertow GM, Dalrymple LS, Kaysen GA, Kornak J, Johansen KL: Association of self-reported frailty with falls and fractures among patients new to dialysis. Am J Nephrol 2015;42:134-140, Epub ahead of print.

13 Painter P and Kuskowski M: A closer look at frailty in ESRD: getting the measure right. Hemodialysis Int 2013;17:41-49.

14 Johansen KL, Dalrymple LS, Delgado C, Kaysen GA, Kornak J, Grimes B, Chertow GM: Comparison of self-report-based and physical performance-based frailty definitions among patients receiving maintenance hemodialysis. Am J Kidney Dis 2014;64:600-607.

15 Dalrymple LS, Katz R, Rifkin DE, Siscovick D, Newman AB, Fried LF, Sarnak MJ, Odden MC, Shlipak MG: Kidney function and prevalent and incident frailty. Clin J Am Soc Nephrol 2013;8:2091-2099.

16 Roshanravan B, Khatri M, Robinson-Cohen C, Levin G, Patel KV, de Boer IH, Seliger S, Ruzinski J, Himmelfarb J, Kestenbaum B: A prospective study of frailty in nephrology-referred patients with CKD. Am J Kidney Dis 2012;60:912-921.

17 Reese PP, Cappola AR, Shults J, Townsend RR, Gadegbeku CA, Anderson C, Baker JF, Carlow D, Sulik MJ, Lo JC, Go AS, Ky B, Mariani L, Feldman HI, Leonard MB: Physical performance and frailty in chronic kidney disease. Am J Nephrol 2013;38:307-315.

18 Kurella Tamura M, Covinsky KE, Chertow GM, Yaffe K, Landefeld CS, McCulloch CE: Functional status of elderly adults before and after initiation of dialysis. N Engl J Med 2009; 361:1539-1547.

19 Jassal SV, Chiu E, Hladunewich M: Loss of independence in patients starting dialysis at 80 years of age or older. N Engl J Med 2009; 361:1612-1613.

20 Johansen KL, Chertow GM, Kutner NG, Dalrymple LS, Grimes BA, Kaysen GA: Low level of self-reported physical activity in ambulatory patients new to dialysis. Kidney Int 2010; 78:1164-1170.

21 Avesani C, Trolonge S, Deléaval P, Baria F, Mafra D, Faxén-Irving G, Chauveau P, Teta D, Kamimura MA, Cuppari L, Chan M, Heimbürger O, Fouque D: Physical activity and energy expenditure in haemodialysis patients: An international study. Nephrol Dial Transplant 2012;27:2430-2434.

22 Matsuzawa R, Matsunaga A, Wang G, Kutsuna T, Ishii A, Abe Y, Takagi Y, Yoshida A, Takahira N: Habitual physical activity measured by accelerometer and survival in maintenance hemodialysis patients. Clin J Am Soc Nephrol 2012;7:2010-2016.

23 Johansen KL, Painter P, Kent-Braun JA, Ng AV, Carey S, Da Silva M, Chertow GM: Validation of questionnaires to estimate physical activity and functioning in end-stage renal disease. Kidney Int 2001;59:1121-1127.

24 O'Hare AM, Tawney K, Bacchetti P, Johansen KL: Decreased survival among sedentary patients undergoing dialysis: results from the dialysis morbidity and mortality study wave 2 . Am J Kidney Dis 2003;41:447-454.

25 Johansen KL, Kaysen GA, Dalrymple LS, Grimes BA, Glidden DV, Anand S, Chertow GM: Association of physical activity with survival among ambulatory patients on dialysis: The comprehensive dialysis study. Clin J Am Soc Nephrol 2013;8:248-253.
26 Bulckaen M, Capitanini A, Lange S, Caciula A, Giuntoli F, Cupisti A: Implementation of exercise training programs in a hemodialysis unit: effects on physical performance. J Nephrol 2011;24:790-797.

27 Nowicki M, Murlikiewicz K, Jagodzińska M: Pedometers as a means to increase spontaneous physical activity in chronic hemodialysis patients. J Nephrol 2010;23:297-305.

28 Johansen KL: Exercise in the end-stage renal disease population. J Am Soc Nephrol 2007; 18:1845-1854.

29 Painter P, Carlson L, Carey S, Paul SM, Myll $\mathrm{J}$ : Low-functioning hemodialysis patients improve with exercise training. Am J Kidney Dis 2000;36:600-608.

30 Johansen KL: Exercise in the end-stage renal disease population. J Am Soc Nephrol 2007; 18:1845-1854.

-31 Delgado C, Doyle JW, Johansen KL: Association of frailty with body composition among patients on hemodialysis. J Ren Nutr 2013;23: 356-362.

32 Johansen KL, Painter PL, Sakkas GK, Gordon P, Doyle J, Shubert T: Effects of resistance exercise training and nandrolone decanoate on body composition and muscle function among patients who receive hemodialysis: a randomized, controlled trial. J Am Soc Nephrol 2006;17:2307-2314.

33 Fiatarone MA, Marks EC, Ryan ND, Meredith CN, Lipsitz LA, Evans WJ: High-intensity strength training in nonagenarians. Effects on skeletal muscle. JAMA 1990;263:3029-3034.

34 Johansen KL, Chertow GM, Jin C, Kutner NG: Significance of frailty among dialysis patients. J Am Soc Nephrol 2007;18:2960-2967.

- 35 Bao Y, Dalrymple L, Chertow GM, Kaysen GA, Johansen KL: Frailty, dialysis initiation, and mortality in end-stage renal disease. Arch Intern Med 2012;172:1071-1077.

36 McAdams-DeMarco MA, Law A, Salter ML, Boyarsky B, Gimenez L, Jaar BG, Walston JD, Segev DL: Frailty as a novel predictor of mortality and hospitalization in individuals of all ages undergoing hemodialysis. J Am Geriatr Soc 2013;61:896-901.

-37 Johansen KL, Dalrymple LS, Delgado C, Kaysen GA, Kornak J, Grimes B, Chertow GM: Association between body composition and frailty among prevalent hemodialysis patients: a US renal data system special study. J Am Soc Nephrol 2014;25:381-389.

38 Shlipak MG, Stehman-Breen C, Fried LF, Song X, Siscovick D, Fried LP, Psaty BM, Newman AB: The presence of frailty in elderly persons with chronic renal insufficiency. Am J Kidney Dis 2004;43:861-867.

39 Wilhelm-Leen ER, Hall YN, K Tamura M, Chertow GM: Frailty and chronic kidney disease: the Third National Health and Nutrition Evaluation Survey. Am J Med 2009;122:664671. 